\title{
RELATIONSHIPS BETWEEN THE MOTORCYCLISTS' BEHAVIOURAL PERCEPTION AND THEIR ACTUAL BEHAVIOUR
}

\author{
Darja Topolšek ${ }^{1}$, Dejan Dragan ${ }^{2}$ \\ ${ }^{1}$ Dept of Technical Logistics, University of Maribor, Celje, Slovenia \\ ${ }^{2}$ Dept of Quantitative Modelling in Logistics, University of Maribor, Celje, Slovenia \\ Submitted 12 March 2015; resubmitted 15 June 2015; accepted 22 July 2015; \\ published online 29 February 2016
}

\begin{abstract}
The paper deals with studying the relationships between the motorcyclists' thinking about proper behaviour and their actual behaviour in the traffic. The impact of some control variables, such as riders' age, experience, driving history, and engine cubature, on actual behaviour, is also addressed here. For the purpose of research, two additional questionnaires were applied besides the well-known Motorcycle Rider Behaviour Questionnaire (MRBQ). To examine the causal relations between all-important latent factors present in this study, the structural equation model was designed. Exploratory and confirmatory factor analyses were also engaged in the analysis and the statistical modelling process. The results show that the higher awareness about alcohol danger and benefits of protective equipment and helmet can noticeably contribute to the bigger traffic safety. Besides, from the results is evident that the control variables are in most cases also significantly interrelated with the actual behaviour factors. The findings of this research could be important for the planning of better traffic safety strategies for the motorcyclists to decrease the fatalities and related costs and traumas.
\end{abstract}

Keywords: motorcycle rider behaviour questionnaire (MRBQ); motorcyclists' behavioural perception; traffic safety; alcohol; factor analysis; structural equation modelling.

\section{Introduction}

If compared with the huge amount of research, conducted in the field of traffic safety about four-wheeled vehicles, relatively little research was carried out in the area of traffic safety of Powered Two Wheelers (PTW). This is particularly true for the motorcycles-related studies. Such a gap could wrongly imply that the motorcycle accidents are negligible, but it is well-known that they are not. On the contrary, the number of traffic accidents with the motorcyclists involved is significant and is even on the rise, while, on the other hand, the total number of traffic accidents is decreasing (OECD 2014).

Riders of powered two-wheelers in the European Union are one of the most vulnerable groups of road users (Šraml et al. 2012). They are quite often involved in road accident and, unfortunately, in many cases can be seriously injured or even killed. Indeed, some studies of motorcycle accidents reported that approximately $96 \%$ of motorcyclists involved in traffic accidents are at great risk to suffer certain injury (Hurt et al. 1981). Moreover, other studies show that even in $50 \%$ of such accidents, serious injuries or even death of the rider occurred (Diamantopoulou et al. 1995).

To offer better traffic safety strategies for the motorcyclists, it is very important to understand the main factors leading to accidents followed by tragic consequences (heavy injuries or death). Unambiguously, riders' errors, decision failures, and the perception failures are some of the most noticeable issues, besides alcohol consumption, driver's age, and wearing protective clothing and a helmet - the Motorcycle Accidents In Depth Study project (MAIDS 2009).

The MAIDS project revealed that $35.9 \%$ of all motorcyclists caused an accident due to the rider's error, $13.2 \%$ of them made decision failures, while $8 \%$ of the accidents were a result of perception failures. Almost $15 \%$ of motorcycle-related accidents ended with a fatal outcome, despite the wearing of the helmet in $98.6 \%$ of all cases, and regardless of relatively insignificant presence of alcohol or drugs (only in $3.3 \%$ cases). The corresponding study also discovered that the number of accidents was related to the age of the rider, the most representative age group being from 26 to 40 years. 
In general, many studies discuss the interrelations between alcohol consumption, protective clothing, helmet wearing, and rider's behaviour on one side, and more or less tragic consequences of road accidents on the other. Alcohol is proved to be related to motorcycle accidents (i.e. Turner, Georggi 2001; Villaveces et al. 2003; Williams 2006). As opposed to other road users, riders are more sensitive to the effects of alcohol since they also have to worry about balance and the coordination of the motorcycle. Lin and Kraus (2009) proposed that a zero limit of the blood alcohol concentration should be obligatory since only this legislative measure could ensure the adequate coordination and balance when operating two-wheeled vehicles.

European Union has a standard, which requires the mandatory use of motorcycle gloves, boots, jackets and pants (EC 1989). Several studies reveal that protective clothes reduce the risk of soft tissue injuries, but do not protect against serious injuries (Otte et al. 2002). Some researchers also confirmed that the use of protective clothing is associated with the purpose of riding (De Rome 2006; Watson et al. 2008). In addition to that, it was discovered that the club members' riders more frequently use motorcycle boots and pants than the nonmembers riders (De Rome, Stanford 2006). De Rome et al. (2011) also concluded that riders without protective clothing do not really believe in the practical value of such protection against injury.

The importance of the helmet and its role in preventing head injuries and deaths has been discussed by many scholars (Evans, Frick 1988; Wilson 1989; Gabella et al. 1995; Rowland et al. 1996; Lin et al. 2001; Liu et al. 2004). Many studies have identified head injuries can contribute to an astonishingly high percentage of motorcycle accidents with a fatal outcome, even up to $60 \%$ (Azhar et al. 2014).

The usage of helmets is mandatory in the European Union countries, which results in the high share of their actual use. Therefore, generally, riders wear a helmet due to legislative measures, but their personal opinion about the helmet use is questionable. As it turns out, only a few studies examined the use of helmets in conjunction with the riders' personal opinion about the helmets' usefulness (Rutter et al. 1998; Pileggi et al. 2006; Oginni et al. 2007; Germeni et al. 2009; Ranney et al. 2010). The majority of these studies concluded that riders with no helmets do not truly believe in their protective value. Ranney et al. (2010) concluded that not-always-helmeted and always-helmeted motorcyclists more or less believe in the priceless value of wearing the protective gear and helmet. On the other side, it was also discovered that non-helmet motorcyclists also more frequently show preferences to a riskier behaviour (Chen 2006; Brown et al. 2011; Haworth et al. 2009).

Statistics for Slovenia show, similarly as in other European Union countries that the motorcyclists are at greater risk to be severely injured or even killed in traffic accidents if compared to the car drivers. In Slovenian local terminology, all types of unusual events, which occur on Slovenian roads, are treated, perceived and officially recorded as 'traffic accidents', regardless their nature or possible consequences. For instance, the events with motorcyclists involved, such as falls, slips, collisions, crashes, and other events, are all addressed as traffic accidents, irrespective of their intensity and potential damage, possible injuries, or even tragic consequences.

For Slovenian traffic safety is also discovered that the deceased riders represent a large proportion of the average number of all traffic losses, which appeared to be 63 fatalities per million inhabitants during the last decade (Zanne et al. 2013). According to the official statistics, one of the reasons for such tragic consequences is also interrelated with the very bad condition of most Slovenian roads, which are in many cases deteriorated and insufficiently maintained. In addition to that, the driving culture of road users is still inappropriate, while the traffic volume rapidly increases during the last years (Policija 2014).

Another important fact for Slovenia is that about 600 traffic accidents happened with motorcyclists engaged during the year 2013 (Policija 2014). On one side, this means only $2.5 \%$ of all traffic accidents in Slovenia, but, on the other hand, almost $20 \%$ of the motorcyclists were heavily injured or deceased in these accidents (Policija 2014). Furthermore, the accidents in $43 \%$ of all cases happened because of the riders, among whose $7 \%$ were influenced by the alcohol, while over $95 \%$ of them carried a (mandatory) helmet (Policija 2014). As in the entire European Union area, the most representative age of the riders involved in the accident belonged to the group from 26 to 40 years.

A deeper examination of traffic accidents in Slovenia shows a quite worrying picture, if compared to the majority of European Union countries. According to the 2nd Road Safety PIN Report (Jost et al. 2008), published by the European Transport Safety Council (ETSC) in 2008, Slovenia 'won' the shameful first place regarding the PTW motorcyclists' deaths per billion travelled kilometres in the year 2006 (Šraml et al. 2012). It had the highest number of such kinds of deaths (more than 350, while the average in European Union was 'only' 86). Another very shocking fact for Slovenia is that the risk of a rider being killed in a traffic accident is on average more than 50 times higher than the corresponding risk for a car driver (the European Union average 'only' 18 times) (Jost et al. 2008; Šraml et al. 2012). In addition, as reported by United Nations Economic Commission for Europe - Transport division (UNECE 2015), in the past decade Slovenia had a significantly higher ratio of injured riders per number of registered motorcycles than the majority of other European Union countries. For instance, this ratio was 647/41600 (about 1.5\%) in year 2008, while the European Union average was below 1\% (UNECE 2015; Eurostat 2015). All these facts indicate that the riders are obviously more jeopardised on Slovenian roads and can be more likely involved or even killed in an accident than their counterparts in most other European Union countries.

In order to contribute to the maximal possible reduction of the motorcyclist accidents, it is certainly use- 
ful to get a certain insight into the riders' thinking and perception about his/her driving behaviour and the attitude to the alcohol, usefulness of the protective clothing, and assets of the helmet. In this spirit, the main goal of the paper is to investigate the relationships between the rider's perception about the alcohol, clothing, and helmets on one side, and his/her thinking about the safety and behaviour on the other. In other words, do the drivers behave in the same way as they think they actually do? The latter means the issue, if believing about the danger of drinking alcohol and usefulness of wearing protective clothing and helmet truly result in the safer behaviour of the riders. On the other side, this might be only self-deception, and the truth is completely different from the riders' personal perception. Since practically none similar researches were detected in the existing literature, we believe that the filling of this gap might be one of the major contributions of this paper.

For the purpose of research, an interview was applied among the randomly chosen group of Slovenian motorcyclists. The basis for interviewing was wellknown Motorcycle Rider Behaviour Questionnaire (MRBQ), firstly introduced in the study (Elliott et al. 2007), and later additionally tested in the other studies (Sakashita et al. 2014; etc.). Its main purpose is to measure the riders' behavioural characteristics, such as control and traffic errors, use of safety equipment, and speed violations, as well as to identify how are the latter related to the crash risk (Elliott et al. 2007). The MRBQ consists of 43 items related to the safe or dangerous behaviour of the riders and is usually measured on six or seven points Likert scale. The latest MRBQ studies have discovered that the resulting factor model can be expressed by four significant factors, which are speed violations, errors, safety equipment, and stunts (Sakashita et al. 2014).

In our case, we used only the 5-point Likert scale for the MRBQ items due to the local characteristics. The details about the structure of these items can be found in the scholarly literature (Elliott et al. 2007; Özkan et al. 2006; Sakashita et al. 2014).

Besides the MRBQ, two additional questionnaires were given to the riders for the fulfilment. The first one (questionnaire Q1) was interrelated with the riders' subjective thinking (perception) and was composed of the alcohol based, helmet based, and clothing based items (measured indicator variables). The second one (questionnaire Q2) contained the control single-items, which are age, years of driving, motorcycle engine volume (cubature), mileage per year, safety driving trainings, and the number of experienced accidents.

After the completed interview, the descriptive statistic of the collected data was investigated at first. Then, the preliminary Exploratory Factor Analysis (EFA), Confirmatory Factor Analysis (CFA) and the Structural Equation Modelling (SEM) procedure were applied. These techniques are very powerful statistical modelling tools from the field of multivariate statistical analysis (Kline 2015; Hoyle 2014; Hair et al. 2009; Byrne 2009). They are used in many scientific areas, such as in the social sciences, psychometrics, management, econom- ics, and operations research, as well as in the natural sciences, engineering, marketing research, educational research, and tourism. Occasionally, they have been also used in the traffic safety research, for example, in the studies (Mattsson 2012; Lajunen et al. 2004; Elliott et al. 2007; Özkan et al. 2006).

When the (unmeasured) latent factors and their loadings were adequately extracted from the given items' data by the means of EFA, the preliminary factor model was a result. The latter represented a useful guideline for the further analysis, by which the so-called structural equation model (SEM model) was afterward calculated in two stages.

In the first stage, the so-called measurement part of the model was derived by the means of CFA. Subsequently, in the second stage, the so-called structural part of the model was also constructed, which enabled us to finish the design of the overall SEM model. The latter provided the means to analyse the causal relations between all factors involved in the analysis (MRBQ multiple-item based factors, Q1 multiple-item based factors, and single-item factors of the questionnaire Q2). All the calculations were conducted in the program package IBM ${ }^{\circ}$ SPSS $^{\circ} 21$ and its extension Amos ${ }^{\mathrm{mm}}$ (Byrne 2009; Arbuckle 2012).

\section{Conceptual Framework, Survey and Hypotheses}

\subsection{The Conceptual Framework}

Fig. 1 shows the conceptual framework with the hypothesized model. Forty three (43) items of the MRBQ questionnaire are symbolized by variables $M_{i}, i=1, \ldots, 43$, while the 11 items related to Q1 are denoted by: $A_{i}, i=$ $1, \ldots, 4$ for the alcohol; $C_{i}, i=1, \ldots, 4$ for the motorcycle clothing (protective jacket, trousers, gloves, and boots) and $H_{i}, i=1, \ldots, 3$ for the helmet. The meaning of the latter will be explained in the sequel. Control items of the questionnaire Q2 are also shown in Fig. 1, and so are four MRBQ factors (speed violations, errors, safety equipment, stunts). It is supposed that the further statistical analysis will clearly give us the three factors related to the Q1, which can be entitled by: alcohol, helmet, and clothing (Q1 factors in Fig. 1). We assume that these Q1 factors and the control single-item Q2 factors definitely have a certain impact on the MRBQ factors. Their influences could be marked with the hypothesized paths containing $9 \cdot 4=36$ hypotheses $\tilde{H}_{i}, i=1, \ldots, 36$, each representing the assumed singular impact of Q1 and Q2 factors on the MRBQ factors. Since the number of 36 hypotheses is quite big, we decided to simplify them to the lower number of only seven grouped hypotheses. This way, the following comprised hypotheses have been applied (Fig. 1):

$$
\begin{aligned}
& \hat{H}_{A L C}=\left\{\tilde{H}_{i}\right\}, i=1, \ldots, 4-\text { impact of alcohol factor } \\
& \text { on MRBQ factors; } \\
& \hat{H}_{C L O}=\left\{\tilde{H}_{i}\right\}, i=5, \ldots, 8-\text { impact of clothing fac- } \\
& \text { tor on MRBQ factors; } \\
& \hat{H}_{H E L}=\left\{\tilde{H}_{i}\right\}, i=9, \ldots, 12-\text { impact of helmet factor } \\
& \text { on MRBQ factors; }
\end{aligned}
$$




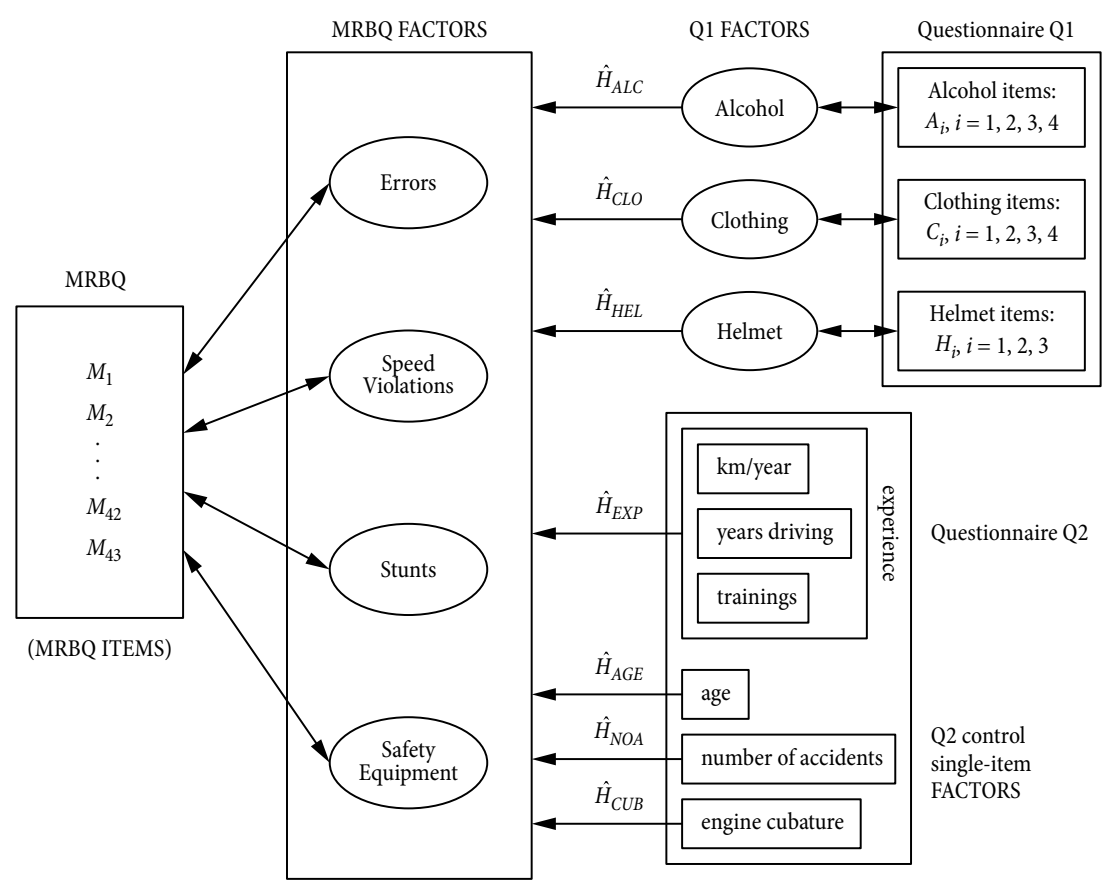

Fig. 1. The conceptual framework (Q1 factors - motorcyclists' subjective opinion about proper behaving; MRBQ factors - motorcyclists' actual behaving)

$\hat{H}_{A G E}=\left\{\tilde{H}_{i}\right\}, i=13, \ldots, 16-$ impact of age factor on MRBQ factors;

$\hat{H}_{\text {EXP }}=\left\{\tilde{H}_{i}\right\}, i=17, \ldots, 28-$ impact of experience on MRBQ factors (comprises years of driving $[\mathrm{km} /$ year], safe driving trainings);

$\hat{H}_{\text {NOA }}=\left\{\tilde{H}_{i}\right\}, i=29, \ldots, 32-$ impact of accidents' factor on MRBQ factors;

$\hat{H}_{C U B}=\left\{\tilde{H}_{i}\right\}, i=33, \ldots, 36$ - impact of engine cubature on MRBQ factors.

From Fig. 1 can be also depicted that the driving experience of the riders' was combined with three characteristics, namely the years of driving, mileage per year [in kilometres], and the frequency of safe driving trainings.

\subsection{Further Explanation of the Settled Hypotheses}

In general, motorcycle riders agree that a definition of safe rider includes the awareness of the danger of highspeed driving and the perception of the importance of the maximal focus on the driving within some reasonable limits. However, the riders often have difficulties with defining or expressing these terms (awareness, perception, focus, limits, and so) (Watson et al. 2007). Some riders also agree that a safe rider should always wear good protective clothing (Watson et al. 2007). However, for instance, do they actually wear the motorcycle clothing as they think they should do, or they are just fooling themselves and the others?

Nevertheless, the thinking about a certain thing is not always the same as truly doing this thing. To discover the possible discrepancy between riders' thinking and their truly performing/behaving, the hypotheses in the previous section could be also defined in the following way:
$\hat{H}_{A L C}=$ \{motorcyclist, who is aware of the danger of alcoholic drinking, is a safer rider\};

$\hat{H}_{C L O}=$ \{motorcyclist, who is aware of the benefits of protective clothing usage, is a safer rider\};

$\hat{H}_{H E L}=$ \{motorcyclist, who is aware of the benefits of helmet usage, is a safer rider $\}$;

$\hat{H}_{A G E}=\{$ older motorcyclists are safer riders $\} ;$

$\hat{H}_{E X P}=$ \{more experienced motorcyclists are safer riders\};

$\hat{H}_{N O A}=\{$ motorcyclists, who have had a traffic accident, are the safer riders\};

$\hat{H}_{C U B}=$ motorcyclists, who drive more powerful motorcycles, are more dangerous riders\}.

When defining the precise interpretation of these hypotheses, the help offered by the interviewed riders was very useful. Therefore, based on their answers and comments, it was supposed that the higher level of awareness of the importance of helmets, clothing, and non-drinking alcohol encourages the riders to drive more carefully. Similarly, their personal opinion about the age, experience, engine cubature and frequency of already occurred accidents was considered not only in the hypotheses' construction, but also in the questionnaires' design.

\subsection{Variables and Design of the Questionnaire Q1}

The meaning of item variables of the questionnaire Q1 is shown in Table 1. As mentioned, this questionnaire is designed to recognize the subjective opinion of the motorists about the danger of alcohol consumption, the benefits of using the motorcycle helmets, and the usefulness of the protective clothing, respectively. For measur- 
Table 1. Subjective opinion based items of the questionnaire Q1

\begin{tabular}{|c|l|}
\hline Item & \multicolumn{1}{|c|}{ Mlcohol items } \\
\hline \multicolumn{1}{|c|}{} & \multicolumn{1}{|c|}{ Measure } \\
\hline$A_{1}$ & not consuming alcohol while driving \\
\hline$A_{2}$ & $\begin{array}{l}\text { drinking the alcohol increases the likelihood of par- } \\
\text { ticipation in a traffic accident }\end{array}$ \\
\hline$A_{3}$ & $\begin{array}{l}\text { motorcyclists are more sensitive to the effects of alco- } \\
\text { hol compared to other drivers since they also have to } \\
\text { worry about the balance }\end{array}$ \\
\hline$A_{4}$ & $\begin{array}{l}\text { motorcyclists are more sensitive to the effects of alco- } \\
\text { hol compared to other drivers since they also have to } \\
\text { worry about the coordination of the motor }\end{array}$ \\
\hline$C_{1}$ & $\begin{array}{l}\text { motorcyclists are involved in a car accident since the } \\
\text { car drivers did not see them, or they have seen them } \\
\text { too late to avoid the collision }\end{array}$ \\
\hline$C_{2}$ & $\begin{array}{l}\text { protective clothing reduces the damage of the skin and } \\
\text { soft tissues }\end{array}$ \\
\hline$C_{3}$ & $\begin{array}{l}\text { protective clothing reduces the deep and extensive } \\
\text { injuries }\end{array}$ \\
\hline$C_{4}$ & $\begin{array}{l}\text { protective clothing reduces the time needed for the } \\
\text { recovery after the injury happened }\end{array}$ \\
\hline$H_{3}$ & $\begin{array}{l}\text { it is essential to have well-attached helmet on the head } \\
\text { since it can fall off in the case of an accident }\end{array}$ \\
\hline$H_{1}$ & $\begin{array}{l}\text { helmet saves lives and prevents the damage of the } \\
\text { brain/skull }\end{array}$ \\
\hline$H_{2}$ & \begin{tabular}{l} 
helmet use reduces the severity of the neck injuries \\
\hline
\end{tabular} \\
\hline
\end{tabular}

ing the Q1 variables, the Likert ordinal scale from 1 to 5 was applied ( 1 - completely disagree; 5 - completely agree). The questions related to the clothing were meant in the spirit of better visibility (fluorescent clothing) since the car drivers have more difficulties to see the riders in dark (un-fluorescent) clothing.

\subsection{Design of the Questionnaire Q2}

This questionnaire was designed to evaluate the effect of certain control variables on the behavioural factors, which are related to the motorcyclists' crash risk. After careful consideration, we have decided that the control measures age, years of driving, motorcycle engine cubature, mileage per year, safety driving trainings, and the number of experienced accidents, would be most appropriate for further analysis (Fig. 1). The sample characteristics of measured scale of Q2 control items are shown in Table 2.

\subsection{Participants and the Execution of the Interview}

All the needed data were collected over a 3-week period in the fall of 2014, and this collection was carried out by the means of online surveys. The latter were randomly sent to the most significant motorcycle clubs across Slovenia, which means that we can generally assume that the collected sample was random, unbiased and representative. After the completed survey, 205 fully com-
Table 2. The sample characteristics of measured scale of Q2 control items

\begin{tabular}{|c|c|}
\hline Items/measures & Measured scale \\
\hline Age & $\begin{array}{l}1 \text { - below } 20 \text { years } \\
2 \text { - from } 20 \text { to } 29 \text { years } \\
3 \text { - from } 30 \text { to } 39 \text { years } \\
4 \text { - from } 40 \text { to } 49 \text { years } \\
5 \text { - from } 50 \text { to } 59 \text { years } \\
6 \text { - above } 59 \text { years }\end{array}$ \\
\hline $\begin{array}{l}\text { Years of motorcycle driving } \\
\text { (total years holding the } \\
\text { driving licence) }\end{array}$ & $\begin{array}{l}1 \text { - less than } 1 \text { year } \\
2 \text { - from } 1 \text { to } 2 \text { years } \\
3 \text { - from } 2 \text { to } 5 \text { years } \\
4 \text { - from } 6 \text { to } 10 \text { years } \\
5 \text { - more than } 10 \text { years }\end{array}$ \\
\hline $\begin{array}{l}\text { Engine capacity } \\
\text { (cubic centimetres) }\end{array}$ & $\begin{array}{l}1 \text { - less than } 500 \mathrm{cc} \\
2 \text { - from } 501 \text { to } 1000 \mathrm{cc} \\
3 \text { - from } 1001 \text { to } 1500 \mathrm{cc} \\
4 \text { - more than } 1500 \mathrm{cc}\end{array}$ \\
\hline Kilometres/year & continuous \\
\hline Number of accidents & polytomous \\
\hline Safe driving trainings & $\begin{array}{l}1 \text { - each year } \\
2 \text { only once (when passing } \\
\text { the driving test) } \\
3 \text { - never }\end{array}$ \\
\hline
\end{tabular}

pleted questionnaires were received, which have been afterwards included in the further research. The final sample encompassed $86.3 \%$ males and $13.7 \%$ females. The riders' age distribution is given in Table 3. 34.6\% of all participants did not have motorcycled traffic accidents while $22 \%$ of them were involved in more than three accidents.

The percentage (64.4\%) of observed riders already involved in any kind of accident (including lighter falls, slips, etc.) seems significantly larger than expected, but there are reasons for that. Firstly, as it was already mentioned in the introduction section, Slovenian roads are quite dangerous for the riders to be involved, injured or even killed in an accident. Namely, as it was estimated for the year 2008, about $1.5 \%$ of all motorcyclist population suffered the consequences of injuries of some type.

Secondly, there is a considerably high percentage of individual falls and slips, which are never reported. Specifically, as the Police, medical institutions, and motorcycle clubs claim, the riders often do not report 'minor' individual accidents (without injuries) in which no other vehicles are involved (falls, slips, and so). Most likely, it was the same for our group of riders, who probably treated such unreported minor events as an accident as well, when they filled in the questionnaires.

Thirdly, as found by the authors (Šraml et al. 2012), many PTW accidents occur on the regional state roads with low traffic volume, where PTW riders try to exploit wanton driving and provoking driving capabilities. Probably many of such accidents, particularly those with no serious consequences, are also not reported. Bearing all this in mind, we believe that the accident involvement characteristics of the sample are in accordance with the characteristics of the entire population, so the corresponding sample bias is within the reasonable level. 
Furthermore, careful examination of the literature showed that there are practically no studies available which would address the frequency of all earlier PTW riders' accidents in other European Union countries. To the best of our knowledge, the Continental mobility study from the year 2013 is the only such study. In this study, the recorded accident involvement is similarly high for the German riders, as it was in above-mentioned case of Slovenian motorcyclists (Continental AG 2013). Explicitly, this means that more than half of all German motorists (59\%) were already involved in some accident of any kind during their riding history (Continental AG 2013). On the other side, some studies also reported the percentage of the riders with at least one earlier accident involvement, but the related survey questions were focused on the accidents occurred only during the past year (for example, $11 \%$ of riders already involved in an accident during the previous 12 months were detected in the study Elliott et al. 2007).

Table 3. The riders' age distribution

\begin{tabular}{|c|c|}
\hline Age range [years] & Percent of the sample \\
\hline $40-49$ & 34.3 \\
\hline $50-59$ & 33.5 \\
\hline $30-39$ & 20.0 \\
\hline$>59$ & 6.3 \\
\hline $20-29$ & 5.9 \\
\hline
\end{tabular}

\section{Methods, Analysis and Modelling}

\subsection{Used Methodology}

Fig. 2 illustrates the methods, which were used in the analysis and modelling procedure. At first, the descriptive statistic of the measured data was investigated with emphasis on the analysis of normality. Afterwards, the
EFA was applied as a prior statistical technique to identify the nature of the latent factors (constructs) and to estimate their indicator items' loadings (Hair et al. 2009). This also enabled us to get a preliminary insight into the relationships between the observed, measured items and the corresponding unmeasured latent constructs.

The two-stage design of the structural equation model was the next step in our statistical analysis. In the first stage, the CFA was conducted, which exposed the EFA based theoretical factor model structure to the process of evaluation of measurement theory. This way, the quality of the presumed theoretical factor model fit to the real data was inspected (Hair et al. 2009). When the confirmatory measurement test of the factor model was successfully carried out, the measurement part of the SEM model appeared as a final result of CFA (Hair et al. 2009).

In the second stage, the structural part of the SEM model was also derived by the means of the SEM modelling procedure. The latter represents a very advanced statistical tool, which combines the factor analysis and the multiple regression analysis into the comprehensive modelling technique (Hoyle 2014; Dragan, Topolšek 2014). It also characterizes a generalization of causal path modelling and deals with the analysis of covariance structures (Hoyle 2014; Dragan, Topolšek 2014).

After the derivation of the overall SEM model, the Goodness Of Fit (GOF) measures was also examined, which enabled the testing of model validity and adequacy. The developed SEM model was afterward used to expose the causal directional relations between all factors involved in the study (MRBQ factors, Q1 factors, and Q2 single-item factors). All further details about the methodologies used in our study can be found in the scholarly literature (Kline 2015; Hoyle 2014; Hair et al. 2009; Byrne 2009; Mulaik 2009; Raykov, Marcoulides 2006; Timm 2002).

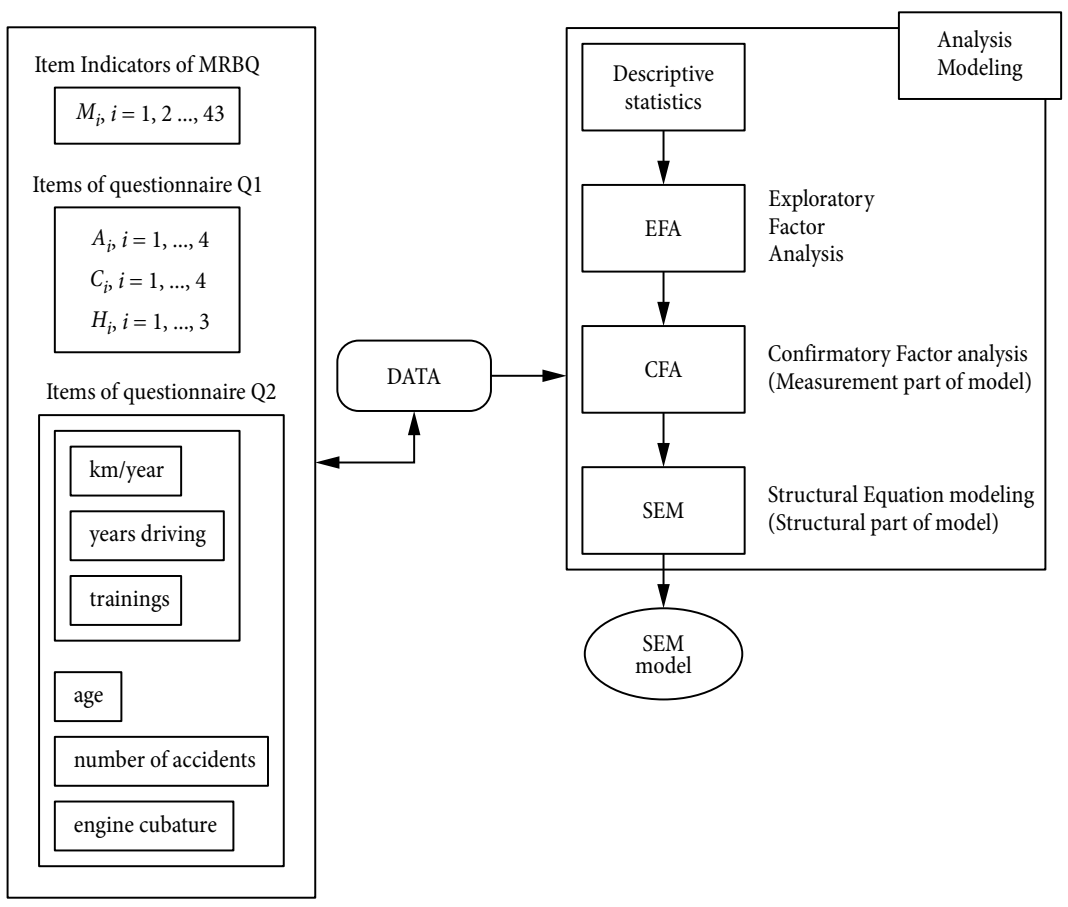

Fig. 2. The block diagram of the used methodology 


\subsection{Estimation Methods}

For the purpose of parameter estimation in the CFA and SEM procedures, a variety of different estimation methods have been developed in the last decades (Kline 2015; Hoyle 2014; Hair et al. 2009; Byrne 2009). The most common is the Maximum Likelihood (ML) estimator, which is usually used when the data are at least approximately normally distributed. Besides, some other typical estimation methods are: un-weighted least square methods, generalized least squares methods, asymptotically distribution-free methods, Bayesian estimation methods, and so (Kline 2015; Hoyle 2014; Byrne 2009).

In our case, the ML method was used in the CFA and SEM since the major indicator variables (those of questionnaires MRBQ and Q1) have had only slight nonnormal distribution. The excuse for applying ML estimator is based on the conclusions of several other studies. Namely, it is reported that the ML estimator gives the suitably accurate estimated parameters, if the ordinal indicator data encompasses at least five stages and are approximately normal (El-Basyouny, El-Bassiouni 2013; Hoyle 2014).

\section{Results of Analysis and Modelling Process}

\subsection{Estimation Methods}

When dealing with the factor analysis and SEM, the studying of normality conditions of observed data is one of the essential issues in the descriptive statistics. The reason is the disturbed accuracy of model validation related statistical tests if the data are severely non-normal (Weston, Gore 2006).

The investigation of non-normality is usually carried-out by the calculation of the Skewness Index (SI) and Kurtosis Index (KI) of the data. There exists certain disagreement in researchers' opinion about the most suitable criterions for the non-normality, which is still acceptable for an effective usage of the ML estimator. However, in general, the researchers agree that the values $|S I|<3$ and $|K I|<7$ are still allowable to apply a ML method without any serious concerns (Zhai et al. 2013; Lei, Lomax 2005; Weston, Gore 2006; Kline 2015; Ullman 2006).

In the case of our data, the normality conditions were not severely violated, but only slightly. The latter means that the skewness indices of corresponding ordinal indicators were positioned inside the interval $(-1.998,1.852)$, while their kurtoses indices have taken the values inside the interval $(-1.551,5.14)$. Therefore, we decided to use the ML estimator since the latter offers quite big spectra of different GOF indices needed in the model validation process.

\subsection{Exploratory Factor Analysis}

As mentioned, the latest research about the 43-item MRBQ questionnaire had implicated that the subsequent factor model can be articulated by four essential factors, which are speed violations, errors, safety equipment, and stunts (Sakashita et al. 2014). Moreover, since we know that the Q1 questionnaire additionally brings three groups of items $\left(A_{i}, i=1, \ldots, 4 ; C_{i}, i=1, \ldots, 4\right.$; $\left.H_{i}, i=1, \ldots, 3\right)$, we justifiably expect that the EFA will clearly give us the seven-factor solution. By other words, it is anticipated that the three additional factors related to the Q1 (alcohol, helmet, and clothing) will occur separately from the four MRBQ factors, so the seven-factor solution will be the most likely outcome of the EFA.

The possibility that the factor analysis may be used without any concerns was verified by the application of two tests: Kaiser-Meyer-Olkin (KMO) test and the Bartlett's Test of Sphericity (BTS) (Hoyle 2014; Kline 2015; Hair et al. 2009). The BTS value was noticeably significant $\left(\chi^{2}=2777.971\right.$ with $d f=465$ and $\left.p<0.001\right)$, while the $\mathrm{KMO}$ value was $0.743>0.5$. According to the recommendation of some authors (Li et al. 2013; Frohlich, Westbrook 2001; Sahin et al. 2013), the achieved BTS and KMO values imply that the EFA can be reliably conducted in the further research.

In the factors' extraction process, the Principal Axis Factoring (PAF) algorithm, with additional Promax rotation (and Kaiser normalization) was executed. For choosing the optimal number of extracted factors, three criterions were used: the Cattell's scree plot, the Kaiser's 'eigen value bigger than one rule', and the calculation of percentage of variation (Hoyle 2014; Kline 2015). Naturally, only those items were retained in the model, which are significantly loaded on corresponding factors (which means: loadings $\lambda_{i j}>0.40$, according to Hair et al. (2009)).

The results of the rotated factor pattern matrix (loadings, Cronbach's alphas (CAs) and the percent of the total variance explained) are presented in Table 4. Since the CAs of all revealed factors are bigger than the value 0.7 , the reliability and internal consistency are adequate (Hair et al. 2009). Cumulative percent of the total variance explained $(61.017 \%)$ is slightly low since 23 illfitting items were dropped because of bad communalities and/or inappropriate loadings' properties. However, according to Hair et al. (2009), this is not a big problem since in the social sciences the total variance explained is often as low as 50-60\% (Williams et al. 2010).

As expected, from Table 4 is clear that the alcoholrelated items $A_{i}$ are significantly loaded on the factor 'alcohol' and the clothing-related items $C_{i}$ are significantly loaded on the factor 'clothing', while the helmet relateditems $H_{i}$ are significantly loaded on the factor 'helmet'. In addition to that, the MRBQ related items $M_{i}$ are significantly on the corresponding MRBQ factors ('errors', 'speed violations', 'stunts' and 'safety equipment'). Thus, we indeed achieved the seven-factor model solution, as it was a priori assumed. This structure based on seven factors will now represent a useful theoretical guideline for the subsequent CFA.

\subsection{Confirmatory Factor Analysis}

As mentioned in earlier sections, the CFA is the first stage of creating the structural equation model (Fig. 2). When conducting the CFA, the structure of the previously derived factor model from the EFA was applied as a baseline. 
Table 4. Achieved results of the rotated factor pattern matrix (EFA - Exploratory Factor Analysis)

\begin{tabular}{|c|c|c|c|c|c|c|c|}
\hline \multirow{2}{*}{ Pattern matrix } & \multicolumn{7}{|c|}{ Factors } \\
\hline & Safety equipment & Errors & Stunts & Helmet & Clothing & Speed violations & Alcohol \\
\hline Cronbach alpha & 0.808 & 0.733 & 0.785 & 0.850 & 0.799 & 0.790 & 0.818 \\
\hline$\%$ of variance & 18.053 & 11.270 & 8.162 & 7.090 & 6.653 & 5.387 & 4.401 \\
\hline Cumulative \% & 18.053 & 29.324 & 37.486 & 44.575 & 51.228 & 56.615 & 61.017 \\
\hline Items & \multicolumn{7}{|c|}{ Item loadings on factors } \\
\hline$M_{30}$ & 0.884 & & & & & & \\
\hline$M_{31}$ & 0.801 & & & & & & \\
\hline$M_{29}$ & 0.751 & & & & & & \\
\hline$M_{32}$ & 0.575 & & & & & & \\
\hline$M_{40}$ & 0.565 & & & & & & \\
\hline$M_{3}$ & & 0.694 & & & & & \\
\hline$M_{1}$ & & 0.601 & & & & & \\
\hline$M_{5}$ & & 0.583 & & & & & \\
\hline$M_{16}$ & & 0.518 & & & & & \\
\hline$M_{11}$ & & 0.485 & & & & & \\
\hline$M_{7}$ & & 0.461 & & & & & \\
\hline$M_{2}$ & & 0.444 & & & & & \\
\hline$M_{6}$ & & 0.434 & & & & & \\
\hline$M_{25}$ & & & 0.739 & & & & \\
\hline$M_{27}$ & & & 0.680 & & & & \\
\hline$M_{28}$ & & & 0.642 & & & & \\
\hline$M_{23}$ & & & 0.620 & & & & \\
\hline$M_{26}$ & & & 0.540 & & & & \\
\hline $\mathrm{H}_{2}$ & & & & 0.970 & & & \\
\hline$H_{1}$ & & & & 0.885 & & & \\
\hline $\mathrm{H}_{3}$ & & & & 0.635 & & & \\
\hline$C_{2}$ & & & & & 0.964 & & \\
\hline$C_{3}$ & & & & & 0.772 & & \\
\hline$C_{4}$ & & & & & 0.587 & & \\
\hline$M_{19}$ & & & & & & 0.887 & \\
\hline$M_{18}$ & & & & & & 0.740 & \\
\hline$M_{20}$ & & & & & & 0.543 & \\
\hline$M_{21}$ & & & & & & 0.427 & \\
\hline$A_{4}$ & & & & & & & 0.941 \\
\hline$A_{3}$ & & & & & & & 0.841 \\
\hline$A_{2}$ & & & & & & & 0.471 \\
\hline
\end{tabular}

The CFA procedure checked if this structure is consistent with the measurement theory. To do so the ML method was used for the estimation of all model parameters at first. While estimating the parameters, the difference between the data-based covariance matrix, and the model implied covariance matrix was minimized (Hoyle 2014).

Afterward, the fitting adequacy of the estimated CFA factor model was examined through the computation of several fit indices, which are usually suggested in the scholarly literature (Kline 2015; Byrne 2009; Hoyle 2014; Hair et al. 2009). Some of the most typical indices are, for instance (Byrne 2009): Normed Fit Index (NFI), Tucker-Lewis Index (TLI), Comparative Fit Index (CFI), Incremental Fit Index (IFI), Root Mean Square Error of Approximation (RMSEA), Standardized Root Mean Residual (SRMR) and so. As it turned out, all of these indices have taken the adequate value with respect to their threshold ranges, which are recommended in the literature (Hooper et al. 2008; Hair et al. 2009; Kline 2015; Hoyle 2014).

To complete the CFA, the derived model had to be evaluated for its convergent and discriminant validity as well. The main issues of the appropriate convergent validity are the adequate Composite Reliability (CR) and Average Variance Extracted (AVE), respectively. Their threshold levels are 0.70 for CR, and 0.5 for AVE (Hair et al. 2009). When the discriminant validity is taken into the consideration, the AVE of each factor should be bigger than the squared correlation $C O R R^{2}$ between this factor and any other factor, or $(\sqrt{A V E}>C O R R)$ (Hair et al. 2009; Fornell, Larcker 1981). As it turned out, the $\mathrm{CR}$ values for all seven factors were inside the interval $(0.715,0.862)$, while the AVE values for all seven factors were inside the interval $(0.504,0.628)$. Since also the 
condition $\sqrt{A V E}>C O R R$ was fulfilled for each crosscorrelation pair of factors, we concluded that there were no validity concerns.

When the CFA was successfully completed, its final result, the measurement part of the SEM model, was used in the further SEM modelling procedure.

\subsection{Structural Equation Model}

\subsubsection{Structure of the Model}

In the second stage of the SEM model construction, its structural part had to be also derived in the SEM modelling process (Fig. 2). Both parts, the structural part and the measurement part, represented the entire structure of the SEM model, which is conceptually consistent with the framework in Fig. 1. Besides the estimated parameters of the SEM model, the SEM procedure also identified all directed causal paths between the addressed factors, as well as their regression weights.
While processing the SEM modelling procedure, the single-item control constructs (Q2 factors, Fig. 1) were also incorporated into the entire SEM model structure. As in the case of CFA, the ML method was used for the parameter estimation, and model fit indices were calculated to test the model adequacy.

Table 5 shows the achieved values of the most important fit indices (see rightmost column) and their threshold values. According to the guidelines of many researchers (Byrne 2009; Hoyle 2014; Hair et al. 2009; Kline 2015; Nunkoo, Ramkissoon 2012, etc.), it was concluded that the fit indices have taken the appropriate values. Therefore, we can presume that the calculated SEM model gives the results, which can provide the reasonably good fit to the real data.

Fig. 3 shows the standardized structural equation model with the estimated path coefficients significant at $p \leq 0.10$ level (see also Fig. 1). Such SEM model illustration represents the main construction of all important

Table 5. Calculated fit indices of the constructed SEM model

\begin{tabular}{|l|l|l|c|}
\hline \multicolumn{1}{|c|}{ Fit index } & \multicolumn{1}{|c|}{ Acceptable threshold levels } & \multicolumn{1}{c|}{ Description } & Achieved \\
\hline$\chi^{2}$ & $\begin{array}{l}\text { Low value relative to degrees of freedom } d f \\
\left(\frac{\chi^{2}}{d f}\right)\end{array}$ & $\begin{array}{l}\text { Chi-Square } \chi^{2} \text { of the discrepancy between the sample } \\
\text { and the fitted covariance matrices }\end{array}$ & 25.377 \\
\hline RMSEA & $\begin{array}{l}<0.07 \text { good } \\
0.07<0.10 \text { moderate } \\
>0.10 \text { bad }\end{array}$ & Relative Chi-Square $\chi^{2}$ of the discrepancy & 1.154 \\
\hline NFI & $\begin{array}{l}>0.90 \text { acceptable } \\
>0.95 \text { good }\end{array}$ & Root Mean Square Error of Approximation & 0.027 \\
\hline NNFI (TLI) & $\begin{array}{l}>0.95 \text { good } \\
>0.90 \text { acceptable }\end{array}$ & Normed-Fit Index & 0.954 \\
\hline CFI & $>0.90$ acceptable & Non-Normed-Fit Index (Tucker-Lewis Index) & 0.969 \\
\hline IFI & $\begin{array}{l}>0.90 \text { acceptable } \\
>0.95 \text { good }\end{array}$ & Comparative Fit Index & 0.993 \\
\hline SRMR & $<0.08$ good & Bollen's Incremental Fit Index & 0.994 \\
\hline
\end{tabular}

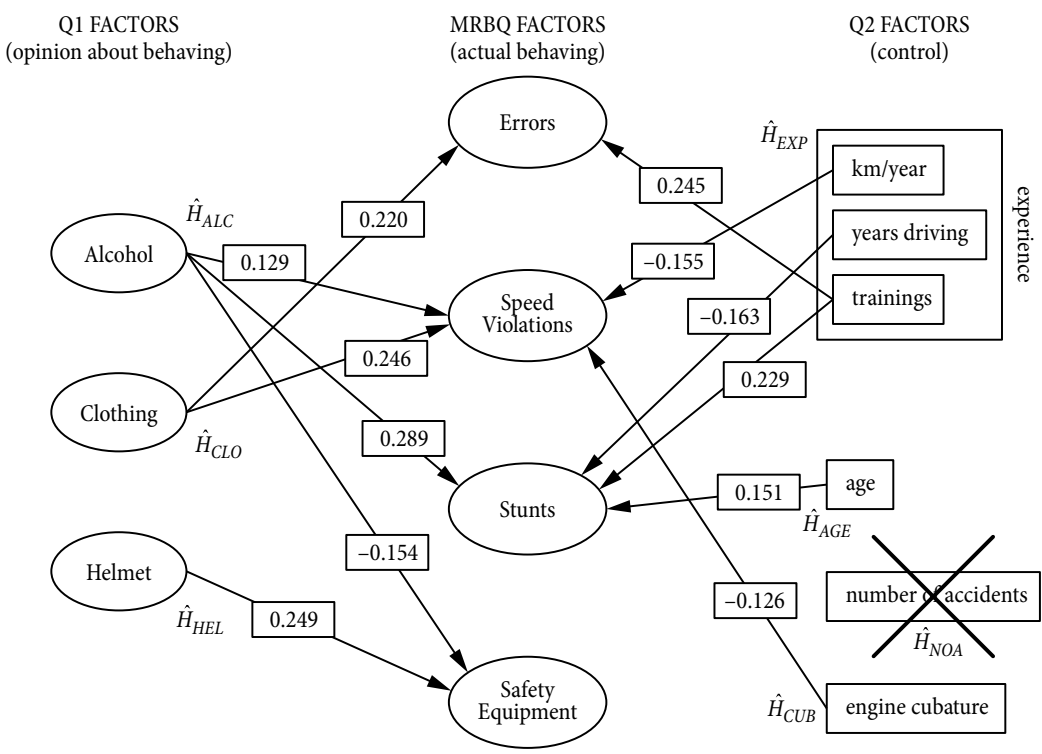

Fig. 3. The relationships between the factors of the standardized SEM model 
relationships between the factors, which are present in this study. Insignificant paths are not shown in Fig. 3 to make the model more transparent. Those paths, which are significant, have the corresponding standardized weights marked, and the grouped hypotheses from expressions (1) and (2) are also shown in Fig. 3. The latter are based on multiple singular hypotheses (each for one connection between the addressed factors), so they should be considered as a whole. By other words, this means that the fully supported grouped hypothesis consists of all supported singular hypotheses. On the other side, the strength of grouped hypothesis confirmation drops with the higher number of unsupported singular hypothesis.

\subsubsection{Confirmation or Rejection of Settled Hypotheses}

The grouped hypotheses, which are given in the expressions (1) and (2), can be commented as follows (Fig. 3):

1) $\hat{H}_{A L C}=\{$ motorcyclist, who is aware of the danger of alcoholic drinking, is a safer rider\}:

The paths from the factor 'alcohol' to the factors 'speed violations' and 'stunts' are positively weighted. Therefore, indeed the higher awareness about the alcohol danger positively contributes to the safer driving in the sense of avoiding the speed violations and stunts. On the contrary, the path from the factor 'alcohol' to the factor 'safety equipment' is negatively weighted. Thus, surprisingly, it looks like that the riders who are more aware of the alcohol danger do not use all the safety equipment. Maybe they contemptuously think why all the clothing should be needed if they are sober, and nothing can happen to them.

2) $\hat{H}_{C L O}=$ \{motorcyclist, who is aware of the benefits of protective clothing usage, is a safer rider\}:

Due to the two positively weighted paths from the factor 'clothing' to the factors 'errors' and 'speed violations', we can conclude that the higher awareness about protective clothing benefits also positively contributes to the safer driving in the sense of avoiding the speed violations and errors. The latter means that motorcyclist highly aware of the importance of motorcycle clothing usage is actually also the safer driver.

3) $\hat{H}_{H E L}=$ \{motorcyclist, who is aware of the benefits of helmet usage, is a safer rider\}:

This hypothesis is in general only partially supported since we have only one positively weighted path from the factor 'helmet' to the factor 'safety equipment.' From this, we can conclude that the rider who is using a helmet (mandatory in Slovenia), also more strictly uses the other protective clothing.

4) $\hat{H}_{A G E}=$ \{older motorcyclists are safer riders $\}$ :

This hypothesis is in general only partially supported since we have only one positively weighted path from the control factor 'age' to the factor 'stunts'. From this, we can conclude that the rider who is older also more mature thinks about uselessness of this kind of behaviour.
5) $\hat{H}_{E X P}=$ \{more experienced motorcyclists are safer riders\}:

This grouped hypothesis can lead us to diverse conclusions if looked from the perspective of the entire experiences' point of view. Namely, the singular hypotheses might imply quite different conclusions. On one side, the paths from the control factor 'trainings' to the factors 'errors' and 'stunts' are positively weighted, which means that the rider with the training lessons does fewer errors and stunts. On the other hand, the paths from the control factors 'km/year' and 'years driving' to the factors 'speed violations' and 'stunts', respectively, are negatively weighted. This implies that the motorcyclist with more travelled kilometres per year is more prone to the speed violations, while the rider with more years of driving is more disposed to the stunts' making, probably because of the greater arrogance.

If the conclusions based on the hypothesis $\hat{H}_{E X P}$ are compared with some previous studies, they only partially give the similar outcomes. Namely, for instance, in some other studies is reported that the lower level of driving experience is linked to the increased risk of accident and the injuries (Ballesteros, Dischinger 2002; Wong et al. 1990). Moreover, some researchers claim that the riders with the safe driving trainings do not characterize a significant risk reduction of causing an accident (Mortimer 1984; Namdaran, Elton 1988; Rutter, Quine 1996). Our belief about this issue is a little different. Namely, on the basis of our research, it might be also concluded that the advanced training can be very useful in the function of traffic safety. However, this is most likely only in the case, if the motorcyclist is faced with the simulated dangerous situations and possible hazards during the trainings.

To summarize the comment on the hypothesis $\hat{H}_{E X P}$, our opinion is that diverse driving experiences without doubt contribute to the safer driving but only inside the limits without the careless, sloppy driving and unnecessary arrogance.

6) $\hat{H}_{N O A}=$ \{motorcyclists, who have had a traffic accident, are the safer riders\}:

Surprisingly, this hypothesis is not confirmed at all since there are not any significant paths existing between the factor 'number of accidents' and the MRBQ factors. Therefore, despite the possible accident, in which the rider perhaps has been involved in the past, he is still driven, in the same way. This sounds quite impossible, especially when the motorcyclist already experienced a car accident with serious outcomes. Therefore, we believe that the drivers, who really suffered consequences related to serious injuries, were not completely honest about the issues, which are related to this hypothesis. Conversely, the riders, who experienced minor falls and slips without injuries, are probably still equally self-confident when riding and did not learn anything from their previous unpleasant experiences. 
7) $\hat{H}_{C U B}=$ \{motorcyclists, who drive more powerful motorcycles, are more dangerous riders\}:

This hypothesis is in general only partially supported since we have only one positively weighted path from the control factor 'engine cubature' to the factor 'speed violations'. From this, we can conclude that the rider, who has a more powerful motorcycle, actually drives slower. The reason is maybe hidden in the increased awareness that a more powerful machine can lead to the more unpredictable and dangerous movements with more serious consequences if the accident happens.

\section{Conclusions}

The paper addresses the relationships between the motorcyclists' thinking and perception about their behaviour and safety issues while riding on one side and their actual behaviour in the traffic on the other side. Additionally, the influence of some control variables (riders' age, experience, engine volume, and the number of previous accidents) on the riding behaviour is also studied.

Riders are one of the most exposed road users and are often involved in traffic accidents with serious consequences. Therefore, it is crucial to recognize the critical factors, when the tragic occasions appear. As we have emphasized, rider errors, as well as decision and perception failures, are some of the most significant behavioural characteristics in the course of events that lead to the rider's road accident.

In addition, the fact is that alcohol drinking avoidance and protective equipment usage (clothing and helmet) can significantly reduce the tragic consequences of traffic accidents involving motorcyclists. However, another question is if the riders' subjective belief about the helpfulness of being sober and well protected with the clothing and helmet can additionally contribute to their safer driving.

In our research, the survey has been carried out among the randomly chosen group of Slovenian motorcyclists, who have received three questionnaires. The first one was a well-known MRBQ questionnaire, which measured the riders' behavioural characteristics in relation to the crash risk. The second one measured the riders' subjective thinking about the usefulness of avoiding alcohol and protecting themselves by wearing helmets and protective clothing. The third one measured the control variables such as age of the rider, years of driving, motorcycle engine volume, and so on.

In order to study the impact of extracted alcoholbased, clothing-based, and helmet-based subjective perception factors on the actual riders' behavioural (MRBQ) factors, a structural equation model was developed. The latter also revealed several causal relations between control single-item factors and the MRBQ factors.

The main purpose of SEM model was to investigate the correctness of seven hypotheses settled in the conceptual framework, which are related to:

- alcohol;

- protective clothing;
- helmet;

- age;

- experience;

- number of previous accidents;

- motorcycle volume.

The results for the first hypothesis show that the higher consciousness about alcohol danger positively contributes to the avoidance of speed violations and stunts. The results for the second hypothesis imply that greater awareness about protective clothing is interrelated with a lower level of speed violations and riders' errors. Regarding the third hypothesis, the research discloses that riders wearing helmets also more strictly use other protective equipment and are therefore more careful. The fourth hypothesis is also confirmed, since older riders more maturely think about the pointlessness of stunts. The fifth hypothesis is related to the studying of relationships between experience based control items and the MRBQ factors. The results here imply quite diverse conclusions. On one side, riders with more training lessons do fewer errors and stunts while on the other side motorcyclists with more travelled kilometres per year are more inclined to over-speed. In addition, some riders with longer driving histories are probably more arrogant since they are more predisposed to perform stunts. Surprisingly, the sixth hypothesis is not confirmed at all. This leads us to the conclusion that the riders, who already experienced one or more serious accidents, were not completely honest with us. On the contrary, we believe that the riders, who had only minor falls and slips, are still equally self-confident when riding and did not become safer. Finally, concerning the seventh hypothesis, the research discovered that riders with more powerful motorcycles actually drive slower, probably because of the increased awareness of the potential danger, related to the powerfulness of their two-wheelers.

Based on our findings, we believe that we managed to achieve the main aim of the paper, which is the investigation of fitting of riders' perception about certain issues on one side, and their actual traffic performance on the other side. As it is evident from testing of first three hypotheses, such kind of fitting is mostly confirmed, so the higher awareness about alcohol danger and benefits of protective equipment and helmet indeed can contribute to the bigger traffic safety.

The major contribution of the present study is filling the gap in the literature with regard to the examination of the relationships between riders' behavioural perception and their actual behaviour. Naturally, the results of our study can be generalized only within the scope of comparable European countries with similar general traffic safety conditions and similar behavioural perception characteristics of the road users. In other words, the results can be useful for those countries, which have a similar combination of several circumstances, as for example: PWT riders' injury and fatality risk rate; traffic density; ratio between the number of PTW and the number of other vehicles; characteristics of roads and the level of their deterioration; and, finally, similar overall driving culture and behaviour properties of the road users. In 
our opinion, according to (Eurostat 2015; Jost et al. 2008; UNECE 2015), our findings might be most suitable for the following comparable European Union countries: Croatia, Estonia, Latvia, Romania, Cyprus, Hungary, and maybe some others. For those countries, that have a higher level of behavioural perception and responsibility related traffic patterns, as well as a more sophisticated driving culture, the results of this study must be used with some caution. In addition, the findings should be treated with certain care for those countries, having a significantly different traffic safety characteristics, such as better and well maintained roads, lower PWT riders' injury and fatality risk rate, etc. In this context, particular caution should be taken in the case of traffic safe and developed countries like Finland and Denmark (EU members), as well as Norway and Switzerland (non-EU members).

Future work based on the results of the present research could investigate the performance of the derived SEM model for riders from different countries in the framework of an international research that would offer the opportunity for additional checking of the consistency and adequacy of the present findings.

\section{References}

Arbuckle, J. L. 2012. IBM ${ }^{\circ}$ SPSS $^{\circ}$ Amos $^{\mathrm{Tm}} 21$ User's Guide. IBM $^{2}$ Corporation. 680 p. Available from Internet: ftp://public. dhe.ibm.com/software/analytics/spss/documentation/ amos/21.0/en/Manuals/IBM_SPSS_Amos_Users_Guide. pdf

Azhar, H.; Ariffin, A. H.; Syazwan, S. M.; Wong, S. V. 2014. Estimating energy absorbing performance of motorcycle safety helmet, Applied Mechanics and Materials 663: 574-578. http://dx.doi.org/10.4028/www.scientific.net/AMM.663.574

Ballesteros, M. F.; Dischinger, P. C. 2002. Characteristics of traffic crashes in Maryland (1996-1998): differences among the youngest drivers, Accident Analysis \& Prevention 34(3): 279-284. http://dx.doi.org/10.1016/S0001-4575(01)00023-9

Brown, C. V. R.; Hejl, K.; Bui, E.; Tips, G.; Coopwood, B. 2011. Risk factors for riding and crashing a motorcycle unhelmeted, The Journal of Emergency Medicine 41(4): 441-446. http://dx.doi.org/10.1016/j.jemermed.2009.07.024

Byrne, B. M. 2009. Structural Equation Modeling with AMOS: Basic Concepts, Applications, and Programming. 2nd edition. Routledge. 416 p.

Chen, H.-B. 2006. Injury patterns and risk factors of motorcycle crashes, Journal of Clinical Rehabilitative Tissue Engineering Research 10: 187-190. (in Chinese).

Continental AG. 2013. German Motorists Want Automated Freeway Driving. Mobility Study 2013. Available from Internet: http://www.continental-corporation.com

De Rome, L. 2006. The injury reduction benefits of motorcycle protective clothing, in NTSB Public Forum on Motorcycle Safety, 12-13 September 2006, Washington, US, 1-15.

De Rome, L.; Ivers, R., Haworth, N., Heritier, S.; Du, W.; Fitzharris, M. 2011. Novice riders and the predictors of riding without motorcycle protective clothing, Accident Analysis \& Prevention 43(3): 1095-1103.

http://dx.doi.org/10.1016/j.aap.2010.12.018

De Rome, L.; Stanford, G. 2006. Motorcycle protective clothing: fashion or function?, in 2006 International Motorcycle
Safety Conference (IMSC), 28-30 March 2006, Long Beach, California, US, 1-14.

Diamantopoulou, K.; Brumen, I.; Dyte, D.; Cameron, M. 1995. Analysis of Trends in Motorcycle Crashes in Victoria. Report No 84. Monash University Accident Research Centre. 126 p. Available from Internet: http://www.monash.edu/ miri/research/reports/muarc084

Dragan, D.; Topolšek, D. 2014. Introduction to structural equation modeling: review, methodology and practical applications, in The 11th International Conference on Logistics \& Sustainable Transport 2014, 19-21 June 2014, Celje, Slovenia, 1-27.

EC. 1989. Council Directive 89/686/EEC of 21 December 1989 on the Approximation of the Laws of the Member States Relating to Personal Protective Equipment. 21 p. Available from Internet: http://eur-lex.europa.eu/legal-content/en/ ALL/?uri=CELEX:31989L0686

El-Basyouny, K.; El-Bassiouni, M. Y. 2013. Modeling and analyzing traffic safety perceptions: an application to the speed limit reduction pilot project in Edmonton, Alberta, Accident Analysis \& Prevention 51: 156-167. http://dx.doi.org/10.1016/j.aap.2012.11.009

Elliott, M. A.; Baughan, C. J.; Sexton, B. F. 2007. Errors and violations in relation to motorcyclists' crash risk, Accident Analysis \& Prevention 39(3): 491-499. http://dx.doi.org/10.1016/j.aap.2006.08.012

Eurostat. 2015. Motorcycles, by Power of Vehicles. Available from Internet: http://ec.europa.eu/eurostat/en/web/products-datasets/-/road_eqs_motorc

Evans, L.; Frick, M. C. 1988. Helmet effectiveness in preventing motorcycle driver and passenger fatalities, Accident Analysis \& Prevention 20(6): 447-458. http://dx.doi.org/10.1016/0001-4575(88)90043-7

Fornell, C.; Larcker, D. F. 1981. Evaluating structural equation models with unobservable variables and measurement error, Journal of Marketing Research 18(1): 39-50. http://dx.doi.org/10.2307/3151312

Frohlich, M. T.; Westbrook, R. 2001. Arcs of integration: an international study of supply chain strategies, Journal of Operations Management 19(2): 185-200. http://dx.doi.org/10.1016/S0272-6963(00)00055-3

Gabella, B.; Reiner, K. L.; Hoffman, R. E.; Cook, M.; Stallones, L. 1995. Relationship of helmet use and head injuries among motorcycle crash victims in El Paso County, Colorado, 1989-1990, Accident Analysis \& Prevention 27(3): 363-369. http://dx.doi.org/10.1016/0001-4575(94)00079-2

Germeni, E.; Lionis, C.; Davou, B.; Petridou, E. T. 2009. Understanding reasons for non-compliance in motorcycle helmet use among adolescents in Greece, Injury Prevention 15(1): 19-23. http://dx.doi.org/10.1136/ip.2008.019356

Hair, J. F.; Black, W. C.; Babin, B. J.; Anderson, R. E. 2009. Multivariate Data Analysis. Prentice Hall. 816 p.

Haworth, N.; Greig, K.; Nielson, A. 2009. Comparison of risk taking in moped and motorcycle crashes, Transportation Research Record: Journal of the Transportation Research Board 2140: 182-187. http://dx.doi.org/10.3141/2140-20

Hooper, D.; Coughlan, J.; Mullen, M. 2008. Structural equation modelling: guidelines for determining model fit, Electronic Journal of Business Research Methods 6(1): 53-60.

Hoyle, R. H. 2014. Handbook of Structural Equation Modeling. The Guilford Press. 740 p.

Hurt, H. H.; Ouellet, J. V.; Thom, D. R. 1981. Motorcycle Accident Cause Factors and Identification of Countermeasures. Volume 1: Technical report. Contract No DOT- 
HS-5-01160. Traffic Safety Center, University of Southern California, Los Angeles. 435 p. Available from Internet: http://isddc.dot.gov/OLPFiles/NHTSA/013695.pdf

Jost, G.; Popolizio, M.; Allsop, R.; Eksler, V. 2008. Countdown to 2010: Only Two More Years to Act! 2nd Road Safety PIN Report. European Transport Safety Council (ETSC). 83 p. Available from Internet: http://archive.etsc.eu/documents/ copy_of_copy_of_2nd\%20PIN\%20Annual\%20Report $\% 20$ 2008.pdf

Kline, R. B. 2015. Principles and Practice of Structural Equation Modeling. 4th edition. The Guilford Press. $534 \mathrm{p}$.

Lajunen, T.; Parker, D.; Summala, H. 2004. The Manchester driver behaviour questionnaire: a cross-cultural study, Accident Analysis \& Prevention 36(2): 231-238. http://dx.doi.org/10.1016/S0001-4575(02)00152-5

Lei, M.; Lomax, R. G. 2005. The effect of varying degrees of nonnormality in structural equation modeling, Structural Equation Modeling: a Multidisciplinary Journal 12(1): 1-27. http://dx.doi.org/10.1207/s15328007sem1201_1

Li, J.; Zhou, L.; Zhu, D.; Hu, C.; Zhang, X.; Xu, Y. 2013. Chinese version of the nursing students' perception of instructor caring (C-NSPIC): assessment of reliability and validity, Nurse Education Today 33(12): 1482-1489. http://dx.doi.org/10.1016/j.nedt.2013.05.017

Liu, B. C.; Ivers, R.; Norton, R.; Boufous, S.; Blows, S.; Lo, S. K. 2004. Helmets for preventing injury in motorcycle riders, Cochrane Database of Systematic Reviews 1: CD004333. http://dx.doi.org/10.1002/14651858.CD004333.pub3

Lin, M.-R.; Hwang, H.-F.; Kuo, N.-W. 2001. Crash severity, injury patterns, and helmet use in adolescent motorcycle riders, The Journal of Trauma and Acute Care Surgery 50(1): 2430. http://dx.doi.org/10.1097/00005373-200101000-00004

Lin, M.-R.; Kraus, J. F. 2009. A review of risk factors and patterns of motorcycle injuries, Accident Analysis \& Prevention 41(4): 710-722. http://dx.doi.org/10.1016/j.aap.2009.03.010

MAIDS. 2009. In-Depth Investigations of Accidents Involving Powered Two Wheelers. Motorcycle Accidents in Depth Study (MAIDS). Available from Internet:

http://www.maids-study.eu

Mattsson, M. 2012. Investigating the factorial invariance of the 28-item DBQ across genders and age groups: an exploratory structural equation modeling study, Accident Analysis \& Prevention 48: 379-396.

http://dx.doi.org/10.1016/j.aap.2012.02.009

Mortimer, R. G. 1984. Evaluation of the motorcycle rider course, Accident Analysis \& Prevention 16(1): 63-71. http://dx.doi.org/10.1016/0001-4575(84)90007-1

Mulaik, S. A. 2009. Linear Causal Modeling with Structural Equations. Chapman and Hall/CRC. 468 p.

Namdaran, F.; Elton, R. A. 1988. A study of reported injury accidents among novice motorcycle riders in a Scottish region, Accident Analysis \& Prevention 20(2): 117-121. http://dx.doi.org/10.1016/0001-4575(88)90027-9

Nunkoo, R.; Ramkissoon, H. 2012. Structural equation modelling and regression analysis in tourism research, Current Issues in Tourism 15(8): 777-802. http://dx.doi.org/10.1080/13683500.2011.641947

OECD. 2014. Road Accidents. http://dx.doi.org/10.1787/2fe1b899-en

Oginni, F. O.; Ugboko, V. I.; Adewole, R. A. 2007. Knowledge, attitude, and practice of Nigerian commercial motorcyclists in the use of crash helmet and other safety measures, Traffic Injury Prevention 8(2): 137-141. http://dx.doi.org/10.1080/15389580601058472
Otte, D.; Schroeder, G.; Richter, M. 2002. Possibilities for load reductions using garment leg protectors for motorcyclists: a technical, medical and biomechanical approach, in Association for the Advancement of Automotive Medicine 46th Annual Conference, 30 September - 2 October 2002, Tempe, Arizona, US, 367-385.

Özkan, T.; Lajunen, T.; Summala, H. 2006. Driver behaviour questionnaire: a follow-up study, Accident Analysis \& Prevention 38(2): 386-395. http://dx.doi.org/10.1016/j.aap.2005.10.012

Pileggi, C.; Bianco, A.; Nobile, C. G. A.; Angelillo, I. F. 2006. Risky behaviors among motorcycling adolescents in Italy, The Journal of Pediatrics 148(4): 527-532. http://dx.doi.org/10.1016/j.jpeds.2005.11.017

Policija. 2014. Letna poročila o delu policije. Statistika. Available from Internet: http://www.policija.si/index.php/statistika (in Slovenian).

Ranney, M. L.; Mello, M. J.; Baird, J. B.; Chai, P. R.; Clark, M. A. 2010. Correlates of motorcycle helmet use among recent graduates of a motorcycle training course, Accident Analysis \& Prevention 42(6): 2057-2062. http://dx.doi.org/10.1016/j.aap.2010.06.017

Raykov, T.; Marcoulides, G. A. 2006. A First Course in Structural Equation Modeling. 2nd edition. Psychology Press. 248 p.

Rowland, J.; Rivara, F.; Salzberg, P.; Soderberg, R.; Maier, R.; Koepsell, T. 1996. Motorcycle helmet use and injury outcome and hospitalization costs from crashes in Washington State, American Journal of Public Health 86(1): 41-45. http://dx.doi.org/10.2105/AJPH.86.1.41

Rutter, D. R.; Quine, L. 1996. Age and experience in motorcycling safety, Accident Analysis \& Prevention 28(1): 15-21. http://dx.doi.org/10.1016/0001-4575(95)00037-2

Rutter, D. R.; Quine, L.; Albery, I. P. 1998. Perceptions of risk in motorcyclists: unrealistic optimism, relative realism and predictions of behaviour, British Journal of Psychology 89(4): 681-696. http://dx.doi.org/10.1111/j.2044-8295.1998.tb02710.x

Sahin, M.; Todiras, A.; Nijkamp, P.; Neuts, B.; Behrens, C. 2012. A structural equations model for assessing the economic performance of high-tech ethnic entrepreneurs, in R. Capello, T. P. Dentinho (Eds.). Globalization Trends and Regional Development: Dynamics of FDI and Human Capital Flows, 211-258. http://dx.doi.org/10.4337/9781781003046.00017

Sakashita, C.; Senserrick, T.; Lo, S.; Boufous, S.; De Rome, L.; Ivers, R. 2014. The motorcycle rider behavior questionnaire: psychometric properties and application amongst novice riders in Australia, Transportation Research Part F: Traffic Psychology and Behaviour 22: 126-139. http://dx.doi.org/10.1016/j.trf.2013.10.005

Šraml, M.; Tollazzi, T.; Renčelj, M. 2012. Traffic safety analysis of powered two-wheelers (PTWs) in Slovenia, Accident Analysis \& Prevention 49: 36-43. http://dx.doi.org/10.1016/j.aap.2011.12.013

Timm, N. H. 2002. Applied Multivariate Analysis. Springer. $695 \mathrm{p}$.

Turner, P. A.; Georggi, N. 2001. The motorcycle-alcohol crash problem in Florida: identification of characteristics and countermeasures, in 2001 International Motorcycle Safety Conference (IMSF), 1-4 March 2001, Orlando, Florida, US, $1-18$.

Ullman, J. B. 2006. Structural equation modeling: reviewing the basics and moving forward, Journal of Personality Assessment 87(1): 35-50. http://dx.doi.org/10.1207/s15327752jpa8701_03 
UNECE. 2015. 2015 Statistics of Road Traffic Accidents in Europe and North America. United Nations Economic Commission for Europe (UNECE). 148 p. Available from Internet: http://www.unece.org/index.php?id=41891

Villaveces, A.; Cummings, P.; Koepsell, T. D.; Rivara, F. P.; Lumley, T.; Moffat, J. 2003. Association of alcohol-related laws with deaths due to motor vehicle and motorcycle crashes in the United States, 1980-1997, American Journal of Epidemiology 157(2): 131-140. http://dx.doi.org/10.1093/aje/kwf186

Watson, B.; Tunnicliff, D.; White, K.; Schonfeld, C.; Wishart, D. 2007. Psychological and Social Factors Influencing Motorcycle Rider Intentions and Behaviour. Centre for Accident Research and Road Safety (CARRS-Q), Queensland University of Technology. 166 p. Available from Internet: http:// eprints.qut.edu.au/9103/1/road_rgr_200704.pdf

Watson, B.; Wishart, D.; Christie, T. 2008. Canberra Motorcycle Apparel Observation Study. Centre for Accident Research \& Road Safety, Queensland. 27 p.

Weston, R.; Gore, P. A. 2006. A brief guide to structural equation modeling, The Counseling Psychologist 34(5): 719-751. http://dx.doi.org/10.1177/0011000006286345

Williams, A. F. 2006. Alcohol-impaired driving and its consequences in the United States: the past 25 years, Journal of Safety Research 37(2): 123-138.

http://dx.doi.org/10.1016/j.jsr.2006.01.001

Williams, B.; Brown, T.; Onsman, A. 2010. Exploratory factor analysis: a five-step guide for novices, Australasian Journal of Paramedicine 8(3): 1-14.

Wilson, D. C. 1989. The Effectiveness of Motorcycle Helmets in Preventing Fatalities. National Highway Traffic Safety Administration (NHTSA), US Department of Transportation, Washington, DC, NHTSA Technical Report DOT HS 807416.12 p. Available from Internet: http://ntl.bts.gov/ lib/25000/25800/25818/DOT-HS-807-416.pdf

Wong, T.-W.; Lee, J.; Phoon, W.-O.; Yiu, P.-C.; Fung, K.-P.; McLean, J. A. 1990. Driving experience and the risk of traffic accident among motorcyclists, Social Science \& Medicine 30(5): 639-640.

http://dx.doi.org/10.1016/0277-9536(90)90163-M

Zanne, M.; Groznik, A.; Twrdy, E. 2013. Assessment of traffic safety among young people aged 15 to 24 in Slovenia, Promet - Traffic \& Transportation 25(2): 147-156.

http://dx.doi.org/10.7307/ptt.v25i2.1290

Zhai, X.; Liu; A. M. M.; Fellows, R. 2013. Human resource practices in Chinese construction organizations: development of a measurement scale, International Journal of Architecture, Engineering and Construction 2(3): 170-183. http://dx.doi.org/10.7492/IJAEC.2013.016 